\title{
Process Innovation in Public Sector
}

\author{
Ali Khodadad-Saryazdi \\ IRGO (Institut de Recherche en Gestion des Organisations) \\ University of Bordeaux, France \\ ali.khodadad-saryazdi@u-bordeaux.fr
}

\section{Cite this entry as:}

Khodadad-Saryazdi A. (2022) Process Innovation in Public Sector. In: Farazmand A. (eds) Global Encyclopedia of Public Administration, Public Policy, and Governance. Springer, Cham. https://doi.org/10.1007/978-3-319-31816-5_4293-1

\section{Synonyms}

Administrative innovation; Organizational change; Organizational innovation; Organizational technology; Technological innovation; Technology implementation

\section{Definition}

Process innovation is the realization of work activity in a new way, in other words, it is a radical process change initiative (Davenport 1993) that may be due to political, organizational, or resource constraints. Process innovation integrates technological and organizational changes and may result from the advent of new technology in an organization. The implementation of process innovation requires the change and transformation of business processes, equipment, and work habits. This innovation may require the readjustment of administrative, manufacturing, or managerial processes. Process innovation is an outstanding issue in the public sector, but, till now, little attention is paid to its implementation challenges in this sector.

\section{Introduction}

Adoption of innovation results from innovation diffusion and marks the starting point of the implementation process. Nevertheless, an innovation adopted by an organization or some of its members does not necessarily lead to implementation or a successful implementation. Even though the adoption studies can anticipate the innovation absorption capacity, it would be in the implementation phase where the challenges of process change reveal themselves.

Most public organizations challenge social requirements, multiple user exigencies, and resource constraints. The reorganization of services, development of 
synergies, or the introduction of new technologies that disrupt the operators' routines reflect these challenges.

The high performance of the private sector due to the entry of multiple tools has led to the importation of private-sector techniques into the public sector. Over the last few years, new technologies have gradually entered into all activities and induced the need to transform production processes of public services. The interconnection of this transformation with ongoing technologies can offer significant benefits to the public sector and improve the added value of activities. However, despite the reform of the New Public Management, which seeks to make the government more business-like (Hood 1998), the peculiarity of the public sector and its mode of governance require adapting the management of process innovation implementation.

There are several works about the success factors of process change in the private sector, but there is little explanation of how the public sector specificities can influence its implementation. This work highlights the process innovation implementation under the public sectors' restrictions and traits. The objective is to provide a general framework for the implementation of any process innovation type in the public sector. Several proposals are presented in the end. Taking these proposals into account by managers before implementing a technology-based innovation will aid increase implementation success. Researchers can also use the proposals to conduct field research.

\section{Process Innovation: From Adoption to Implementation}

Process innovation is the most widespread innovation in the public sector because of two major convergent movements, new public management (NPM) and e-government (De Vries et al. 2016). However, public organizations seem to be adopters rather than innovators (Djellal et al. 2013). Moreover, because of the functioning of the public sector, innovations are often introduced in a top-down process, which raises the question of how to implement innovation more acutely.

\subsection{At the Origin of the Implementation: The Adoption of Innovation}

Adoption as a decision to implement does not guarantee effective implementation or application. This decision separates the phase of initiation, also called pre-adoption, from that of implementation, also called post-adoption (Damanpour and Schneider 2009). Several sequential models represent the innovation process, but in fact, it seems too complex to separate the stages. Indeed, process innovation is a recommended technique, philosophy, or series of activities that can be implemented in different ways without a unique rule but requires context knowledge. 
In increasingly competitive situations, process innovation can significantly impact productivity and help to gain a competitive advantage by improving organizational efficiency and responsiveness. As examples of process innovation in the public sector, we can mention the e-government (Mensah 2020), Smart Port technologies (Rajabi et al. 2018), the one-stop-shops, e-learning, telemedicine (Khodadad-Saryazdi 2019; 2021), the enterprise resource planning system, or the cargo community systems (Baron and Khodadad-Saryazdi 2021).

\section{Implementation of Process Innovation in Public Organizations}

Adoption and implementation are the challenges related to the introduction of innovation in any organization. The success of the implementation phase does not obey a single rule, so its comprehension requires a thorough knowledge of the specificities and characteristics of the public sphere.

\subsection{Public Sphere}

Process innovation in the public sector is often associated with reform movements, such as new public management (De Vries et al. 2016; Pollitt and Bouckaert 2004) that contributes to legitimize public organizations. Seeking increased performance leads to the introduction of new tools or changes in business practices. Innovation in the public sector is mainly driven by governance improvement and service performance, all for creating public value. Process innovation can both improve the services provided to users and simplify administrative processes (De Vries et al. 2016). However, the initiative to implement process innovation can not only raise the legitimacy of public bodies but also lead to a loss of legitimacy by revealing the gaps or conflicts in the implementation.

The public sector is the collection of organizations, agents, and activities subject to the political system, collective purpose, and strict rules (Ouellet 1994). These criteria indicate the importance of the government's role and its influence on innovation implementation.

The social utility of public organizations can be at the origin of public innovation policies. However, today's degrading image of public service is not irrelevant to the subject. Limiting public bodies' resources influencing the service quality, and introducing the competition, incite the desire to regain. Therefore, innovation can be one of the strategic decision orientations of public organizations. Moreover, public agents have certain rights and obligations. The fact that they work in a strictly regulated environment and are regularized to their position can sometimes affect their work culture vis-à-vis the process change. Culture, not irrelative to public servants' social ideology, can facilitate or complicate process innovation's implementation. 


\subsection{Public Context Characteristics}

Public and private organizations are similar in many respects, but differ fundamentally that can be explained by Core Publicness (Rainey et al. 1976). The basis of this approach is the division between political authority and market incentives, generally used to identify the differences between public and private sectors and examine the possibility of applying certain techniques of private enterprises in public organizations (Rainey and Chun 2007). These differences also have an impact on the organizational posture toward innovations (Koch and Hauknes 2005).

Political and economic authority can affect organizational strategy. The public sector is mainly known for the specific legal status, budget dependence, and non-profit vocation to ensure the missions of general interest, that can encourage public directors to engage in producing goods and services without seeking profits or incentives (Rainey and Chun 2007). Public directors, as well as many public professionals, do not have enough time to think about doing things differently, because they devote a substantial part of their time to responding to political bodies and reporting to the inspection agencies or political leaders (Mulgan and Albury 2003). They are under the permanent control of public authorities, which restrains their activities' liberty. Moreover, complex administrative formalities and long process requests make it complicated to achieve new technologies. These latter are considered the process change enablers, and their absence may inhibit innovation (Koch and Hauknes 2005).

All these restrictions, obligations, and potential risks can increase the hesitation of public organizations in implementing a complex innovation. The public values and objectives can also affect innovation implementation. For instance, some public bodies, like the military, have a rigid structure with a dominant heritage culture, in which the change is considered as a disruption in the organization's functioning, and thus it is preferable to keep intact the processes that function properly (Koch and Hauknes 2005).

Public agents have a reduced motivation to improve performance, but they prioritize organizational commitment and public values (Bullock et al. 2015). Limited motivation plans and financial incentives, as well as budget dependence of public institutions, can decrease organizational performance.

Lack of resources, such as relevant skills, financial resources, and support from other departments, can preclude adoption (Djellal et al. 2013). Nevertheless, these shortages can also obstruct the implementation due to resource underestimation or weak intercommunication. For instance, in some public structures such as public hospitals, the large size and lack of communication between the different departments can complicate the implementation (Koch and Hauknes 2005).

The impact of this compartmentalization is even more evident in public hospitals where the medical and administrative staff do not always have the same priorities in terms of innovation, which can lead to a lack of support, resistance to change, and a decline in organizational learning. 


\subsection{Factors Impacting Process Innovation Implementation in the Public Sector}

The potential situation of process innovation implementation in the public sector has been investigated by the existing intersection between publicness and the implementation success factors. The intersection gave rise to nine proposals that can be validated by future investigations.

Matrix of proposals, Table 1 The interaction of public sector's traits with process innovation success factors

\begin{tabular}{|c|c|c|c|c|c|c|c|}
\hline Public characteristics & $\begin{array}{l}\text { Strategic } \\
\text { alignment }\end{array}$ & Governance & Leadership & Culture & $I T / I S$ & $P A$ & $P E$ \\
\hline State's high influence & & & & P5 & & & \\
\hline $\begin{array}{l}\text { Lack of resources/ } \\
\text { budget dependence }\end{array}$ & & & & & P6 & & \\
\hline $\begin{array}{l}\text { Strict rules/regulated } \\
\text { environment/complex and long } \\
\text { administrative formalities }\end{array}$ & & P3 & & & & & P9 \\
\hline Public values and objectives & $\mathrm{P} 1 / \mathrm{P} 2$ & & & P5 & & P8 & \\
\hline $\begin{array}{l}\text { Limited financial incentives/ } \\
\text { reduced motivation }\end{array}$ & & & & & & P8 & \\
\hline $\begin{array}{l}\text { Limited power, limited } \\
\text { autonomy, and more frequent } \\
\text { changes of public directors }\end{array}$ & & & P4 & & & P7 & \\
\hline Risk aversion & $\mathrm{P} 1 / \mathrm{P} 2$ & & & P5 & & & $\mathrm{P} 9$ \\
\hline Compartmentalization & & & & & P6 & & \\
\hline
\end{tabular}

\subsubsection{Strategic Alignment}

It is the linkage of organizational priorities and processes to achieve business goals (De Bruin and Rosemann 2006). The disjunction between process and strategy can be one of the major failure reasons of the process change projects, but 
when the processes are aligned with the public organization's strategy, it facilitates the change.

The force field in public bodies emanates from government policies with a normative framework on their functioning. If the financial objectives and profit logic encourage private organizations to develop or use innovation, in public ones, the force field and social interest can migrate the strategy toward the implementation of an innovation deemed useful. In the same way, a risky innovation project can be judged as a loss of public funds. Risk aversion in the public sector can be explained by the fear of inadequate consumption of public resources (Kock and Hauknes 2005; Mulgan and Albury 2003). Therefore, process innovation must be closely linked to the strategy to be accepted.

Given that in the public sector, strategic alignment is particularly influenced by political objectives, laws, and people's well-being, a process innovation may be admitted with more interest if its advantages concern both the State and the users. So, we can say that:

Proposal 1. The conformity of process innovation with the policy and laws of society may favor its implementation.

Lack of incentive can reduce motivation toward innovation (Mulgan and Albury 2003). Similarly, if the innovation does not benefit the public organization and agents, it may never become a part of organizational strategic priorities, and even after a period, it can be stopped partly or entirely.

In the public context, there are different stakeholders such as State, public organization, public agents, and users, and their benefits during the process change should not be neglected. Therefore, process innovation must bring advantages for public managers and agents to support its implementation, so:

Proposal 2. The more process innovation is adapted to the requirements of the public body and its agents, the easier would be the implementation.

If the alignment of new processes with the organizational strategy contributes to implementation, reciprocally, the organizational strategy can also support the implementation of new processes. In this context, management can provide a helpful context and support all the necessary dimensions of implementation.

\subsubsection{Governance}

It refers to the management of the process change project and that of process execution. Project governance enables the accomplishment of activities in the given time and minimizing the project problems, but not enough because the effective daily functioning of new processes requires process governance. Therefore, when new processes are implemented, a management system is essential to make them viable, by the creation of structures, performance measurement tools, as well as transparent and appropriate roles and responsibilities (Rosemann and vom Brocke 2015; Spanyi 2015). 
The process change initiative in the public sector requires a detailed project management plan with specific steps and objectives. The development and validation of the project, as well as the provision of resources, sometimes can be very time-consuming due to the rigid structure of the public sector. Furthermore, the fact that public bodies are dependent on the annual budget forces them to prepare a rational economic plan in the short term. Short-termism can hinder significant organizational change because this later usually requires long-term planning (Mulgan and Albury 2003).

Therefore, the strict rules of the public sector may make the implementation more complex. In fact, at the organizational level, public bodies are more or less bureaucratic, and decision-making needs more paperwork. Moreover, the role of public authorities in the management of the public services is accentuated by the central or local administrations, as part of activity control and supervision, consequently, we can say that:

Proposal 3. The administrative procedures and burden can complicate the implementation of process innovation.

\subsubsection{Leadership}

Leadership concerns the manager's support throughout the process change. According to Damanpour and Schneider (2009), leadership in public organizations can create a social climate encouraging staff motivation. The director can also provide necessary resources or coordinate projects. The role of leadership would be even more significant if the project is raised in a bottom-up manner. In the public sector, the frequent change of senior managers can influence the implementation of projects (Rainey et al. 1976). The arrival of a new director can have a significant impact on the popularity of process change, even if the official strategy remains the same (Rosemann and vom Brocke 2015) because each director has his own reasoning. So:

Proposal 4. Frequent change of public managers can impact the implementation of process innovation.

\subsubsection{Culture}

Because of the specific culture and legal status, business process change in a public organization can be more complex than in a private one. Moreover, in the public sector, reforms can affect the implementation of process innovation. As Pollitt and Bouckaert (2004) point out, the reform consists of deliberate changes in structures and processes of public sector organizations to make them run better. Process changes can encourage public agents to be more performance aware. According to the recent research of Mensah (2020), the ability of governments to provide the required regulatory framework and other related policy issues can be useful and even crucial for the implementation of e-government services.

Regardless of the nature of the public sector, the reforms can influence organizational culture by reducing resistance and encouraging public agents to 
cooperate in implementing the process innovation. Reforms can also, sometimes, clarify and simplify the legal requirements of implementation, and so decrease the risks of the process innovation.

Proposal 5. Reforms can act as an enabler in implementing process innovations.

\subsubsection{Information Technologies (IT) and Information Systems (IS)}

Some process innovations in the public sector are highly IT-dependent, and their utilization can bring significant benefits to organizational processes. For example, e-government is one of the IT applications to automate business processes and to create integrated IT infrastructures, or telemedicine which is one of the IT applications in the healthcare sector aimed at improving patients' access to care by modifying traditional medical processes (Khodadad-Saryazdi 2016). Thus, IT can both facilitate process modification and the implementation of process innovation.

Integrated Information Systems (IIS) can contribute to decompartmentalize different units of the public institution, facilitate the creation of integrated processes, and add value to the organizational processes. However, many process innovations are dependent on Integrated Information Technologies (IIT) or IIS or both. The reality of resource and skill shortage in the public sector is not irrelevant to the implementation of IT-dependent or IIS-dependent process innovations. The provision of performant IT equipment requires the budget allocation and the competence for IS interconnection. So, we can say:

Proposal 6. The fact that IT implementation within process innovation requires specific and extra resources can complicate or delay its implementation.

\subsubsection{Process Actors (PA)}

Actors who are directly or indirectly involved in process change are the most valuable asset of an organization for process improvement or innovation (Willaert et al. 2007) in terms of knowledge, competence, commitment, motivation, and loyalty. The essential actors for implementing process innovation are the director and his team, the personnel concerned by new processes, and the project champion.

In the public sector, the implementation of an innovation is often realized in a top-down logic. However, the limited power, restricted autonomy, and more frequent changes of the public directors (Rainey et al. 1976) may lead to a movement by agents to lead a process change. This movement is observed only in certain sectors, where public agents have more autonomy like that of the public hospitals (i.e., healthcare professionals).

Though management support can be crucial for a successful implementation, the interest of public agents in organizational commitment and public values (Bullock et al. 2015) can enable process change. Conversely, it is 
quite possible that the top-down strategies imposed by management, lead to reluctance and resistance by employees. Thus:

Proposition 7. A Bottom-up initiated process innovation is more likely to be implemented successfully and become regular.

Lack of incentives and funding is the barrier to implementing innovation in the public sector (Damanpour and Schneider 2009). Process innovation can improve products or services and so benefit the citizens. Moreover, knowing that human resources remain a determining factor in the implementation of process innovations, it seems that agent's decision empowerment and awareness of the social utility of process innovation can favor its implantation. Consequently:

Proposal 8. Raising the awareness of public agents to the benefits of process innovation can encourage them to cooperate in the implementation.

\subsubsection{Performance Evaluation (PE)}

A process life cycle generally includes four stages of design, configuration, execution, and assessment. Some techniques are useful in each process life cycle, such as modeling and improvement methods (Rosemann et vom Brocke 2015). Performance assessment concerns both process and project evaluation. For Spanyi (2015), performance must be measured from the perspective of users and society. The evaluation of process performance can be considered as a tool for the execution of the organizational strategy (Willaert et al. 2007).

Underutilization of an allocated budget would not be a resource for the public organization because budget surplus must be restored to public resources. This fact can affect the agent's motivation to save and reduce costs (Ouellet 1994). In the public sector, the cost control lever is presented in the mandates and obligations to be respected. Thus, this is quite normal that public bodies are more reluctant to the risks associated with the innovation whose results are uncertain.

The innovation performance evaluation is sometimes very requested in public organizations. These latter are generally worried about the little-known impacts of innovation on the society, citizens, environment, and public funds; nevertheless, some benefits are difficult to quantify.

The dynamic nature of technological elements of process innovation can prevent accurate determination of cost-benefit relationship. Furthermore, before the maturity stage of innovation, it may be hard to estimate its short-term consequences because innovation continues to evolve and adapt to the context.

Proposal 9. Evaluating a process innovation in early stages of adoption may delay its implementation.

\section{Conclusion}

Process innovation, as a subset of organizational innovation, is a new way of doing activities present in different business sectors. It may involve both new 
processes and new technologies, giving it a hybrid image.

Process innovation implementation is still a concern for practitioners and scholars. Process innovation literature in the public sector focuses primarily on process redesigning methods, while in this entry, using the same literature, the implementation conditions of process innovation have been analyzed.

Public values, resources, agents' priorities, decision-making modes, and service structure are decisive elements in the implementation. The latter can be affected by organizational, technical, cultural, or strategic factors. Confronting public features with the factors affecting process innovation implementation has led to several non-exhaustive proposals.

This entry provides a general framework for the implementation of process innovation in the public sector. The proposals can be applied both by practitioners and researchers for any process innovation type. Their legitimacy highly depends on empirical validations, notably by qualitative research, to contextualize them to the targeted sector. Different contexts can offer different outcomes, so proposals should be examined in different public sectors, such as healthcare or national education.

\section{Cross-References}

- Organizational Innovation

- Public Policy and Bureaucracy

- Dynamics of Managerial Innovation

- Organizational Technology

\section{References}

Baron ML, Khodadad-Saryazdi A (2021) Application de la théorie des communs à l'analyse des défis managériaux d'un SIIO: le cas du système de rendez-vous transporteurs au port du Havre. Logistique \& Management 29(1): 34-46

Bullock J B, Stritch J M, Rainey H G (2015) International comparison of public and private employees' work motives, attitudes, and perceived rewards. Public Administration Review 75(3): 479-489

Damanpour F, Schneider M (2009) Characteristics of innovation and innovation adoption in public organizations: Assessing the role of managers. Journal of public administration research and theory 19(3): 495-522

Davenport T H (1993) Process innovation: reengineering work through information technology. Harvard Business Press, Boston, Massachusetts, U.S.A.

De Bruin T. Rosemann M (2006) Towards Understanding Strategic Alignment of Business Process Management. In: Spencer S, Jenkins A (eds.) Proceedings of the 17th Australasian Conference on Information Systems. South Australia, Adelaide, pp 1-10

De Vries H, Bekkers V, Tummers L (2016) Innovation in the public sector: A systematic review and future research agenda. Public administration 94(1): 146-166

Djellal F, Gallouj F, Miles I (2013) Two decades of research on innovation in services: Which place for public services?. Structural change and economic dynamics 27: 98-117

Hood C (1998) The art of the state: culture, rhetoric and public management. Oxford University Press, New York 
Khodadad Saryazdi A (2016) Les barrières et les facteurs de succès à l'implantation d'innovation de processus dans les établissements publics de santé: le cas de la télémédecine en France. Doctoral dissertation, Aix-Marseille

Khodadad-Saryazdi A (2019) La télémédecine, une innovation au service de la logistique hospitalière. In: Fabbe-Costes N, Rouquet A (eds) La logistisation du monde Chroniques sur une révolution en cours. Presses Universitaires d'Aix-Marseille (PUAM), Aix-en-Provence, pp 39-42

Khodadad-Saryazdi A (2021) Exploring the telemedicine implementation challenges through the process innovation approach: A case study research in the French healthcare sector. Technovation 107 (102273)

Koch P, Hauknes J (2005) On innovation in the public sector-today and beyond, (Publin Report). Oslo: D20

Mensah I K (2020) Impact of government capacity and E-government performance on the adoption of E-Government services. International Journal of Public Administration 43(4): 303-311

Mulgan G, Albury D (2003) Innovation in the public sector. Strategy Unit, Cabinet Office 1(40)

Ouellet L (1994) Le secteur public et sa gestion. In: Parenteau R (ed) Management Public : Comprendre et Gérer les Institutions de l'État. Presses de l'Université du Québec, Québec, pp 25-48

Pollitt C, Bouckaert G (2004) Public management reform: A comparative analysis. Oxford University Press, New York

Rainey H G, Backoff R W, Levine C H (1976) Comparing public and private organizations. Public administration review 36(2): 233-244

Rainey H G, Chun Y H (2007) Public and private management compared. In: Ferlie E, Lynn L E, Pollitt C (eds) The Oxford handbook of public management. Oxford University Press, New York, pp 72-102

Rajabi A, Saryazdi A K, Belfkih A, Duvallet C (2018) Towards smart port: An application of AIS data. In: 2018 IEEE 20th International Conference on High Performance Computing and Communications; IEEE 16th International Conference on Smart City; IEEE 4th International Conference on Data Science and Systems (HPCC/SmartCity/DSS), pp 1414-1421.

Rosemann M, vom Brocke J (2015) The six core elements of business process management. In: vom Brocke J, Rosemann M (eds) Handbook on Business Process Management 1. Springer, Berlin Heidelberg, pp 105-122

Spanyi A (2015) The Governance of Business Process Management. In: vom Brocke J, Rosemann M (eds) Handbook on Business Process Management 2. Springer, Berlin Heidelberg, pp 333-349

Willaert P, Van den Bergh J, Willems J, Deschoolmeester D (2007) The process oriented organisation: a holistic view developing a framework for business process orientation maturity. In: Alonso G, Dadam P, Rosemann M (eds.) Business Process Management. Springer, Berlin Heidelberg, pp 1-15 